\title{
Kritische Analyse der Leistungsfähigkeit des Transaktionskostenansatzes
}

\author{
Dissertation \\ zur Erlangung des \\ wirtschaftswissenschaftlichen Doktorgrades \\ der Wirtschaftswissenschaftlichen Fakultät \\ der Universität Göttingen
}

\author{
vorgelegt \\ von \\ Hilmar Döring \\ aus \\ Celle
}

Göttingen 1998 
Erstgutachter: Prof. Dr. G. Schanz

Zweitgutachter: Prof. Dr. G. Kucera

Tag der mündlichen Prüfung: 5. Februar 1999 
Meinen Eltern 